\title{
Relationships Between Skin Autofluorescence and Cardio- Ankle Vascular Index in Japanese Male Patients With Metabolic Syndrome
}

\author{
Takashi Hitsumoto
}

\begin{abstract}
Background: An autofluorescence (AF) reader can be used to noninvasively measure tissues that accumulated advanced glycation endproducts to diagnose skin AF. This study aimed to clarify the clinical significance of skin $\mathrm{AF}$ as a risk factor for cardiovascular disease in Japanese male patients with metabolic syndrome using the cardioankle vascular index (CAVI) as a marker of arterial function.
\end{abstract}

Methods: This cross-sectional study enrolled 261 Japanese male patients with metabolic syndrome without history of cardiovascular disease (mean age, $58 \pm 7$ years (mean \pm standard deviation)). Associations between skin AF and various clinical parameters including CAVI were examined.

Results: Skin AF was significantly positively correlated with CAVI $(\mathrm{r}=0.40, \mathrm{P}<0.001)$. Furthermore, multiple regression analyses revealed that skin $\mathrm{AF}(\beta=0.18, \mathrm{P}=0.002)$ was selected as an independent subordinate factor for CAVI. Meanwhile, homeostatic model assessment of insulin resistance (HOMA-IR) as a marker of insulin resistance, smoking habits and high-sensitivity C-reactive protein as an inflammation marker were independent variables for either CAVI or skin AF as a subordinate factor. According to the receiver-operating characteristic curve analysis and results of previous reports that determined CAVI of $\geq 9.0$ as a diagnostic criterion for vascular failure, skin AF of $>2.7$ arbitrary unit is the optimal cut-off point for discriminating high CAVI (area under the curve $=0.718, \mathrm{P}<0.001$ ).

Conclusion: Findings in this study indicate that skin AF may be an important risk factor of cardiovascular disease in Japanese male patients with metabolic syndrome. In addition, the risk value of skin AF was considered as higher than 2.7 arbitrary unit. Further investigations in a large number of prospective studies, including intervention therapies, are required to validate the results in this study.

Keywords: Skin autofluorescence; Cardio-ankle vascular index; Metabolic syndrome; Insulin resistance; Smoking; Inflammation; Male gender; Japanese

Manuscript submitted April 27, 2019, accepted May 30, 2019

Hitsumoto Medical Clinic, 2-7-7, Takezakicyou, Shimonoseki City, Yamaguchi 750-0025, Japan. Email: thitsu@jcom.home.ne.jp

doi: https://doi.org/10.14740/cr878

\section{Introduction}

Recent clinical and epidemiological studies indicated that patients with metabolic syndrome (Mets) increased worldwide because of changing lifestyle such as the eating or lack of exercise habits $[1,2]$. In addition, the increase of patients with Mets was reportedly associated with increased incidence of cardiovascular disease (CVD), such as ischemic heart disease and stroke [3-5]. Therefore, effective methods should be considered to decrease the number of patients with Mets in daily practice and also explore a novel target factor to prevent CVD events in patients with Mets.

The cardio-ankle vascular index (CAVI) is a novel physiological marker of arteriosclerosis, reflecting arterial stiffness in the aorta, femoral and tibial arteries [6]. In addition, several clinical reports indicate that CAVI reflects endothelial dysfunction considered as reflecting early stage of atherosclerosis $[7,8]$. In recent years, a number of clinical data were accumulated regarding the usefulness of CAVI as a CVD risk factor in various types of population including those with Mets [9-12].

Advanced glycation end-products (AGEs) play an important role in the pathophysiology of various diseases. Among the methods used to evaluate AGEs, skin autofluorescence (AF) is known to be a simple and reliable marker in vivo, and recent clinical studies have indicated that skin AF levels are significantly associated with CVD incidence [13-15]. In addition, researchers reported that skin AF levels were significantly higher in patients with Mets than those with Mets [16]. However, data regarding the usefulness of skin $\mathrm{AF}$ as a CVD risk factor in patients with Mets are limited. Therefore, this crosssectional study attempts to clarify the clinical significance of skin $\mathrm{AF}$ as a risk factor for CVD in patients with Mets using CAVI.

\section{Materials and Methods}

\section{Patients}

Patients in this study were enrolled between September 2015 and August 2018. The study population comprised 261 Japanese male patients with Mets, who visited the Hitsumoto Medical Clinic. Their mean age was $58 \pm 7$ years (mean \pm standard deviation (SD)). Diagnosis of Mets was evaluated according to 


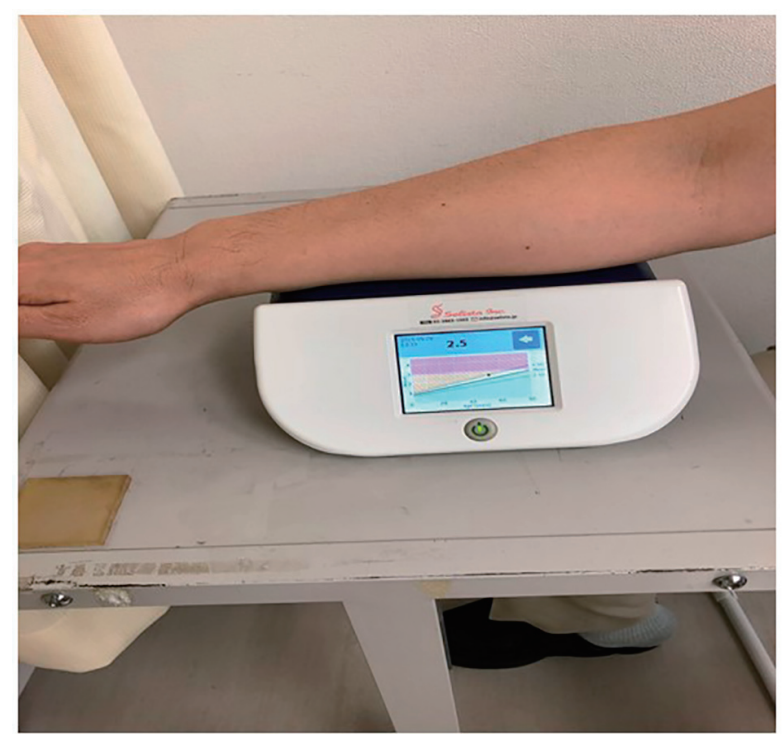

Figure 1. Measuring method of skin AF. Skin AF was automatically measured using a commercial instrument. With patients seated, all measurements were taken at the volar side of the lower arm, approximately $10-15 \mathrm{~cm}$ below the elbow. AF was defined as the average light intensity per nanometer between 300 and $420 \mathrm{~nm}$. The skin AF levels were expressed in arbitrary unit. AF: autofluorescence.

the Japanese criteria. Patients with CVD history or those using medications such as antihyperlipidemic, antihypertensive, or antidiabetic drugs were excluded. This study was conducted in compliance with the ethical standards of the responsible institution on human subjects as well as the Helsinki Declaration. All patients provided informed consent, and the study protocol was approved by the Institutional Review Board of the Hitsumoto Medical Clinic (approval number: 2015-08).

\section{Diagnosis of Mets}

Mets was diagnosed based on the Japanese Committee for the Diagnostic Criteria of Metabolic Syndrome [17]. In the Japanese criteria, Mets was defined as the presence of two or more clinical abnormalities (three abnormalities: dyslipidemia (serum triglyceride concentrations of $\geq 150 \mathrm{mg} / \mathrm{dL}$ and/or serum high-density lipoprotein cholesterol concentrations of $<40$ $\mathrm{mg} / \mathrm{dL}$ ), elevated blood pressure levels (systolic blood pressure of $\geq 130 \mathrm{~mm} \mathrm{Hg}$ and/or diastolic blood pressure of $\geq 85$ $\mathrm{mm} \mathrm{Hg}$ ) and elevated blood glucose levels (fasting blood glucose of $\geq 110 \mathrm{mg} / \mathrm{dL}$ )), in addition to visceral fat obesity (waist circumference of $\geq 85 \mathrm{~cm}$ in men and $\geq 90 \mathrm{~cm}$ in women). Previous studies indicated that Mets evaluated according to the Japanese diagnosis criteria significantly occurs with coronary atherosclerosis or CVD [3, 18].

\section{Skin AF measurement}

Figure 1 shows measuring method of skin AF. Skin AF was automatically measured using a commercial instrument (AGE
Reader $^{\mathrm{TM}}$; DiagnOptics, Groningen, the Netherlands), as previously described $[19,20]$. With patients seated, all measurements were taken at the volar side of the lower arm, approximately $10-15 \mathrm{~cm}$ below the elbow. AF was defined as the average light intensity per nanometer between 300 and 420 $\mathrm{nm}$. The skin AF levels were expressed in arbitrary unit (AU). The levels of pentosidine, a major AGE component, were measured using skin biopsy at the volar side of the lower arm and appeared to be significantly correlated with skin AF [21]. The validity and reliability of skin AF levels in the Japanese population measured using this method have been previously established [20].

\section{CAVI measurement}

Figure 2 shows measuring method of CAVI. CAVI was measured using a VaSera CAVI instrument (Fukuda Denshi, Tokyo, Japan) following the previously described methods [6]. Briefly, the brachial and ankle pulse waves were determined using inflatable cuffs with the pressure maintained between 30 and $50 \mathrm{~mm} \mathrm{Hg}$ to ensure its minimal effect on the systemic hemodynamics. Systemic blood and pulse pressures were simultaneously determined, with the participant in a supine position. CAVI was measured after the participants had rested for 10 $\min$ in a quiet room. For statistical evaluation of the CAVI, mean values of the left and right sides were used. The average coefficient of CAVI variation has been shown to be $<5 \%$, which is small enough for clinical use and indicates that CAVI measurement has good reproducibility [22].

\section{Estimation of cardiovascular risk factors}

The degree of obesity was evaluated using body mass index, calculated as weight $(\mathrm{kg})$ divided by the squared height $\left(\mathrm{m}^{2}\right)$. Smoker was defined as smoking at least one cigarette per day during the last 1 year, and Brinkmen index (number of smoking (/day) $\times$ smoking duration (years)) was used as a marker of smoking exposure. The right brachial blood pressure was measured twice using a mercury sphygmomanometer, with participants in sitting position. An average of two readings was used to determine the systolic and diastolic blood pressures. Blood samples were collected from the antecubital vein in the morning after $12 \mathrm{~h}$ of fasting. Total cholesterol and triglyceride levels were measured using standard enzymatic methods. Serum high-density lipoprotein cholesterol levels were measured using selective inhibition. Serum low-density lipoprotein cholesterol levels were calculated using the Friedewald equation [23]. Glucose and insulin levels were measured using the glucose oxidase method and an enzyme immunoassay, respectively. To measure insulin resistance, homeostatic model assessment of insulin resistance (HOMA-IR) was calculated using the following equation [24]: HOMA-IR = fasting glucose concentration $(\mathrm{mg} / \mathrm{dL}) \times$ fasting insulin concentration $(\mu \mathrm{g} / \mathrm{mL}) / 405$. High-sensitivity C-reactive protein (hs-CRP) concentration as a marker of inflammation was measured using high-sensitivity, latex-enhanced immunonephelometrics. 

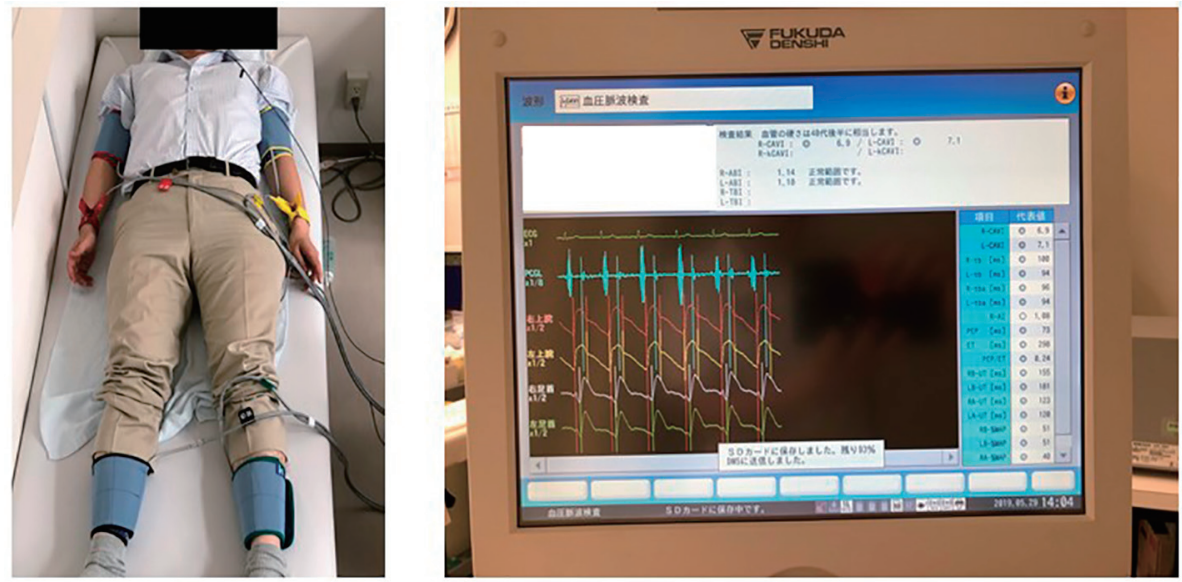

Figure 2. Measuring method of CAVI. The brachial and ankle pulse waves were determined using inflatable cuffs with the pressure maintained between 30 and $50 \mathrm{~mm} \mathrm{Hg}$ to ensure that the cuff pressure had a minimal effect on the systemic hemodynamics. Blood and pulse pressures were determined simultaneously with the subjects lying supine, after they had first rested for 10 min in a quiet room. CAVI was calculated using the following formula: $C A V I=a\{(2 \rho / \Delta P) \times \ln (P s / P d) P W V 2\}+b$, where $a$ and $b$ are constants, $\rho$ is blood density and $\triangle \mathrm{P}$ is $\mathrm{Ps}-\mathrm{Pd}$. CAVI: cardio-ankle vascular index; Ps: systolic blood pressure; Pd: diastolic blood pressure; PWV: pulse wave velocity.

\section{Statistical analysis}

Data were analyzed using the Stat View-J 5.0 (HULINKS, Tokyo, Japan) and MedCalc for Windows version 14.8.1 (MedCalc Software, Ostend, Belgium) and are expressed as mean \pm SD. Between-group comparisons were performed using the Student's $t$-test, and the correlation coefficient was estimated using the Pearson or Spearman rank-order correlation analysis. Multivariate analysis was performed using multiple regression analyses. The receiver-operating characteristic curves were constructed, and the maximum Youden index [25] was used to determine the optimal skin AF cut-off levels of high CAVI. A P-value of $<0.05$ was considered statistically significant.

\section{Results}

\section{Study population}

Table 1 summarizes patient characteristics of this study. The mean value of skin AF was $2.4 \pm 0.6 \mathrm{AU}$ (range, 1.5 - 4.6), and the mean value of CAVI was $8.3 \pm 1.3$ (range, $6.2-12.3$ ). Skin $\mathrm{AF}$ and CAVI have nearly normal distribution.

\section{Correlation between factors}

The correlations between skin AF and CAVI are shown in Figure 3. Significantly positive correlations were observed between these two clinical parameters. Figure 4 shows the relationships between smoking habits and CAVI or skin AF. Both CAVI and skin AF were significantly higher in smokers than in non-smokers. In addition, both CAVI and skin AF were significantly positively correlated with the Brinkman index.
Table 2 presents relationships among CAVI, skin AF and various clinical parameters. Age, systolic blood pressure, fasting blood glucose levels, HOMA-IR, hs-CRP and the number of Mets components were significantly positively correlated with CAVI. On the contrary, age, HOMA-IR and hs-CRP were significantly positively correlated with skin AF.

Table 1. Patient Characteristics

\begin{tabular}{ll}
\hline $\mathrm{n}$ & 261 \\
Age (years) & $58 \pm 7$ \\
Body mass index $\left(\mathrm{kg} / \mathrm{m}^{2}\right)$ & $25.1 \pm 3.1$ \\
West circumference $(\mathrm{cm})$ & $90 \pm 5$ \\
Smoker, $\mathrm{n}(\%)$ & $80(31)$ \\
Systolic blood pressure (mm Hg) & $141 \pm 17$ \\
Diastolic blood pressure (mm Hg) & $84 \pm 13$ \\
Pulse rate (/min) & $72 \pm 11$ \\
Laboratory findings & \\
\hline Total cholesterol (mg/dL) & $226 \pm 43$ \\
$\quad$ LDL-cholesterol (mg/dL) & $141 \pm 40$ \\
Triglyceride (mg/dL) & $204 \pm 59$ \\
HDL-cholesterol (mg/dL) & $44 \pm 14$ \\
Fasting blood glucose (mg/dL) & $113 \pm 18$ \\
HOMA-IR & $2.8 \pm 1.4$ \\
Log-hs-CRP (mg/dL) & $-1.1 \pm 0.5$ \\
Skin AF (AU) & $2.4 \pm 0.6$ \\
CAVI & $8.3 \pm 1.3$ \\
\hline
\end{tabular}

Continuous values are mean \pm SD. LDL: low-density lipoprotein; HDL: high-density lipoprotein; HOMA-IR: homeostasis assessment insulin resistance; hs-CRP: high-sensitivity C-reactive protein; AF: autofluorescence; AU: arbitrary unit; CAVI: cardio-ankle vascular index. 


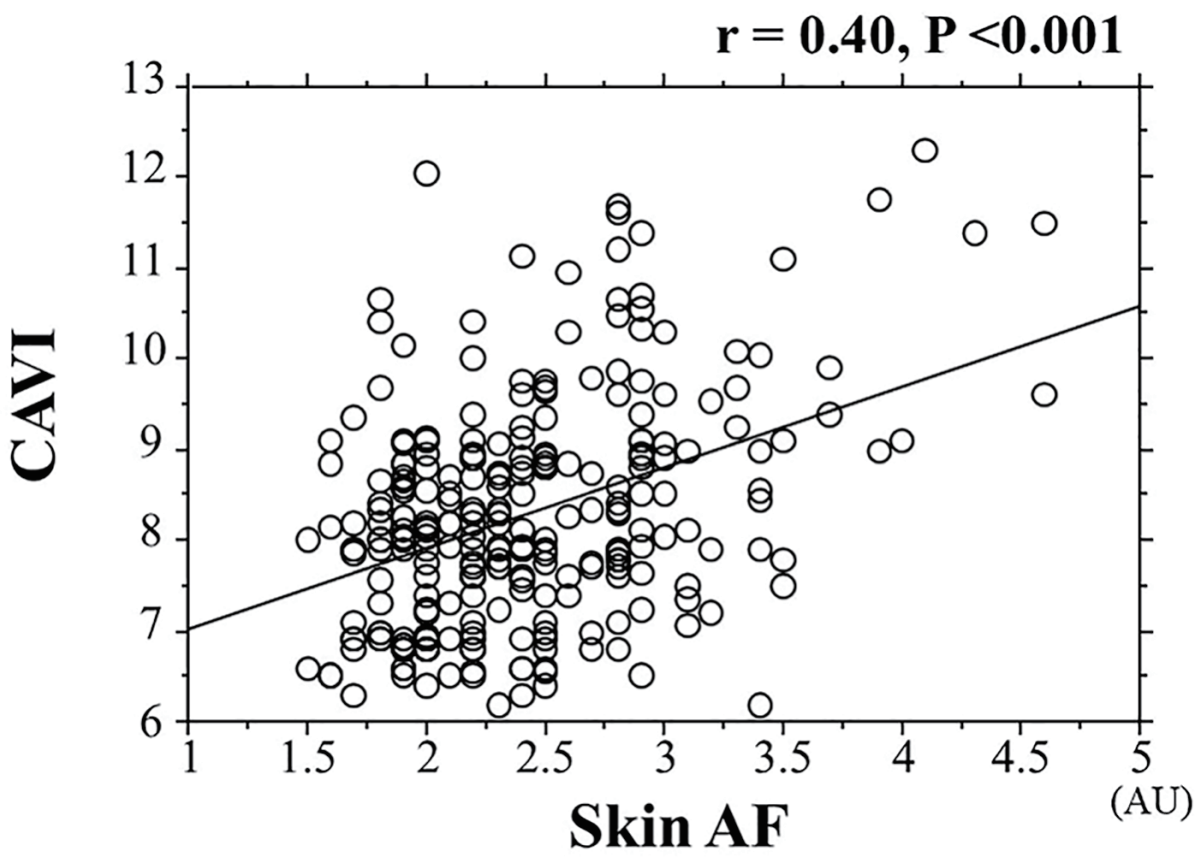

Figure 3. Correlation between skin AF and CAVI. AF: autofluorescence; CAVI: cardio-ankle vascular index; AU: arbitrary unit.

(a)

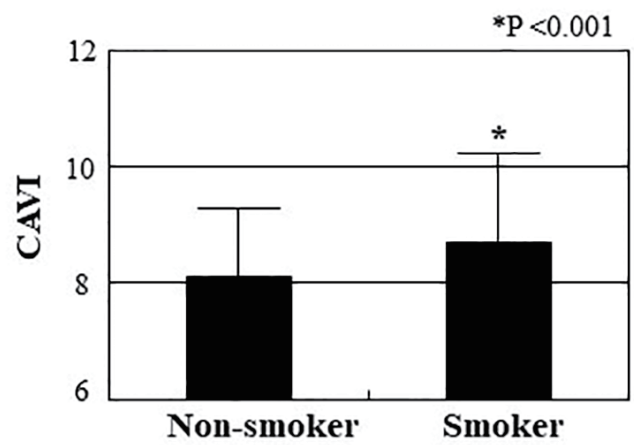

(b)

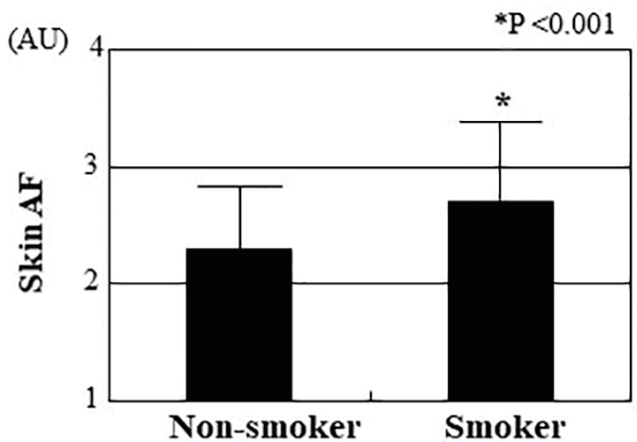

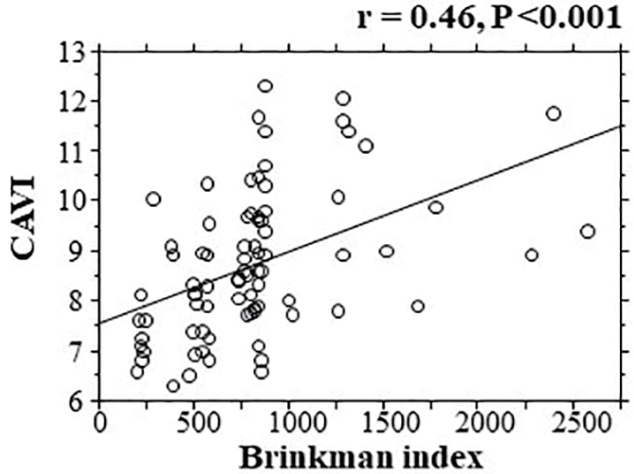

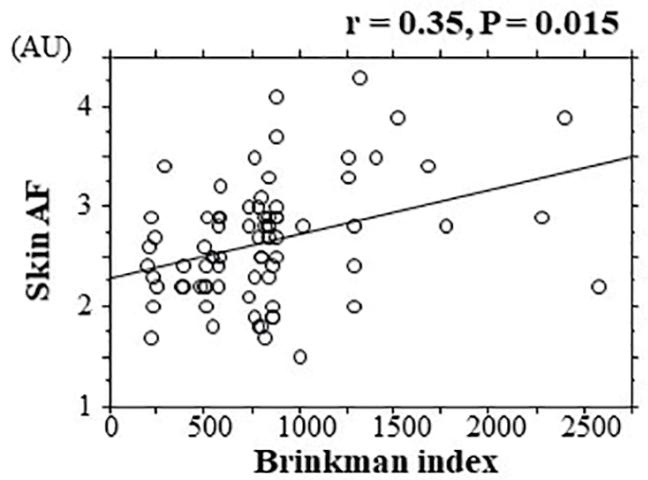

Figure 4. Relations between smoking habits and CAVI and skin AF. Both CAVI (smoker vs. non-smoker: $8.7 \pm 1.4$ vs. $8.1 \pm$ 1.1 , respectively, $P<0.001$ ) and skin $A F$ (smoker vs. non-smoker: $2.7 \pm 0.6 \mathrm{AU}$ vs. $2.3 \pm 0.5 \mathrm{AU}$, respectively, $\mathrm{P}<0.001$ ) were significantly higher in patients who are smokers than in those who are non-smokers. In addition, both CAVI and skin AF were significantly positively correlated with Brinkman index as a marker of smoking exposure. (a) Relations between smoking habits and CAVI. (b) Relations between smoking habits and skin AF. CAVI: cardio-ankle vascular index; AF: autofluorescence; AU: arbitrary unit. 
Table 2. Relationships Among CAVI, Skin AF and Various Clinical Parameters

\begin{tabular}{lll}
\hline & \multicolumn{2}{c}{ r } \\
\cline { 2 - 3 } AgVI & Skin AF \\
\hline Body mass index & $0.48^{* * *}$ & $0.21^{* * *}$ \\
West circumference & 0.10 & 0.08 \\
Systolic blood pressure & 0.05 & 0.03 \\
Diastolic blood pressure & $0.12^{*}$ & 0.08 \\
Pulse rate & 0.08 & 0.10 \\
Total cholesterol & 0.06 & 0.02 \\
LDL cholesterol & 0.03 & 0.02 \\
Triglyceride & 0.05 & 0.02 \\
HDL cholesterol & 0.03 & 0.03 \\
Fasting blood glucose & -0.06 & -0.03 \\
HOMA-IR & $0.18^{* *}$ & 0.10 \\
Log-hs-CRP & $0.24^{* * *}$ & $0.34^{* * *}$ \\
Number of Mets components & $0.33^{* * *}$ & $0.34^{* * *}$ \\
\hline
\end{tabular}

$r$ expressed correlation coefficient. ${ }^{*} P<0.05$, ${ }^{* *} P<0.01$, ${ }^{* * *} P<0.001$. CAVI: cardio-ankle vascular index; AF: autofluorescence; LDL: lowdensity lipoprotein; HDL: high-density lipoprotein; HOMA-IR: homeostasis assessment insulin resistance; hs-CRP: high-sensitivity C-reactive protein; Mets: metabolic syndrome.

\section{Multivariate analysis and receiver-operating characteris- tic curve}

Table 3 summarizes the results of a multiple regression analysis with CAVI or skin AF as a subordinate factor. Explanatory factors were selected by significant variables in univariate analysis. Age, skin AF, smoker, hs-CRP and HOMA-IR were identified as independent variables when CAVI was used as a subordinate factor. On the contrary, HOMA-IR, CAVI, hs-CRP and the smoker were identified as independent variables when skin AF was used as a subordinate factor. Figure 5 shows the receiver-operating characteristic curve analysis for the detection of high CAVI as $\geq 9.0$ based on skin AF. The maximum Youden index indicated that skin AF of $>2.7$ AU was the optimal cut-off point to determine the high CAVI (area under the curve $=0.718, \mathrm{P}<0.001)$ with true positive rate of $55.1 \%$ and false positive rate of $81.2 \%$.

\section{Discussion}

The results in this study indicated that skin AF was significantly positively correlated with CAVI; furthermore, multivariate analysis clarified that these two clinical parameters were independently associated. Previous studies reported that skin AF was significantly associated with physiological marker of arterial function including CAVI in patients with diabetes mellitus or kidney disease [10, 26-28]. In addition, this study also indicated that skin AF is considered as an important factor that affects the
Table 3. Multiple Regression Analysis

\begin{tabular}{lll}
\hline Explanatory factor & $\boldsymbol{\beta}$ & P value \\
\hline (A) & & \\
Age & 0.39 & $<0.001$ \\
Skin AF & 0.18 & 0.002 \\
Smoker & 0.16 & 0.003 \\
Log-hs-CRP & 0.15 & 0.005 \\
HOMA-IR & 0.11 & 0.045 \\
Systolic blood pressure & 0.06 & 0.258 \\
Fasting blood glucose & 0.05 & 0.465 \\
$\quad$ Number of Mets components & 0.03 & 0.570 \\
(B) & & \\
HOMA-IR & 0.24 & $<0.001$ \\
CAVI & 0.21 & 0.002 \\
Log-hs-CRP & 0.19 & 0.007 \\
Smoker & 0.18 & 0.008 \\
Age & 0.06 & 0.343 \\
\hline
\end{tabular}

(A) Subordinate factor is CAVI: $R^{2}=0.39$; $P<0.001$. (B) Subordinate factor is skin AF: $R^{2}=0.29$; $P<0.001$. AF: autofluorescence; hs-CRP: high-sensitivity C-reactive protein; HOMA-IR: homeostatic model assessment of insulin resistance; Mets: metabolic syndrome; CAVI: cardio-ankle vascular index.

arterial function in patients with Mets. On the contrary, HOMAIR as a marker of insulin resistance, smoking habits and hs-CRP as an inflammation marker were selected as independent variables for both CAVI and skin AF as a subordinate factor.

Previous studies have reported that AGEs or their receptors were associated with vascular cell calcification such as endothelial or smooth muscle cells or functional arterial aging [29-31]. In addition, the results in this study that indicate significant relationships between skin AF and CAVI can be interpreted as AGEs acting an important role for arterial function in patients with Mets. On the contrary, a number of studies indicated that insulin resistance acts a critical role in the pathogenesis of Mets. In addition, several researchers reported that insulin resistance affected arterial dysfunction [32, 33]. In this study, HOMA-IR was also significantly related with CAVI in patients with Mets, indicating that insulin resistance also acts an important role for arterial dysfunction. On the contrary, some basic studies indicated that AGEs affected insulin resistance through the several pathways such as AGEs receptor-1, sirtuin-1 and phosphoinositide 3-kinase [34, 35]. The results in this study also indicated that HOMA-IR was selected as one of the strongest variables for skin AF as a subordinate factor. Therefore, an intervention therapy was aggressively performed to reduce AGEs; consequently, CVD events were reduced in patients with Mets by improving insulin resistance.

Smoking habits have been known as one of the important risk factors for CVD incidence. In addition, several studies indicated that complication of smoking habits and Mets was significantly associated with higher CVD incidence risk [36]. The results in this study indicate a significant association between 


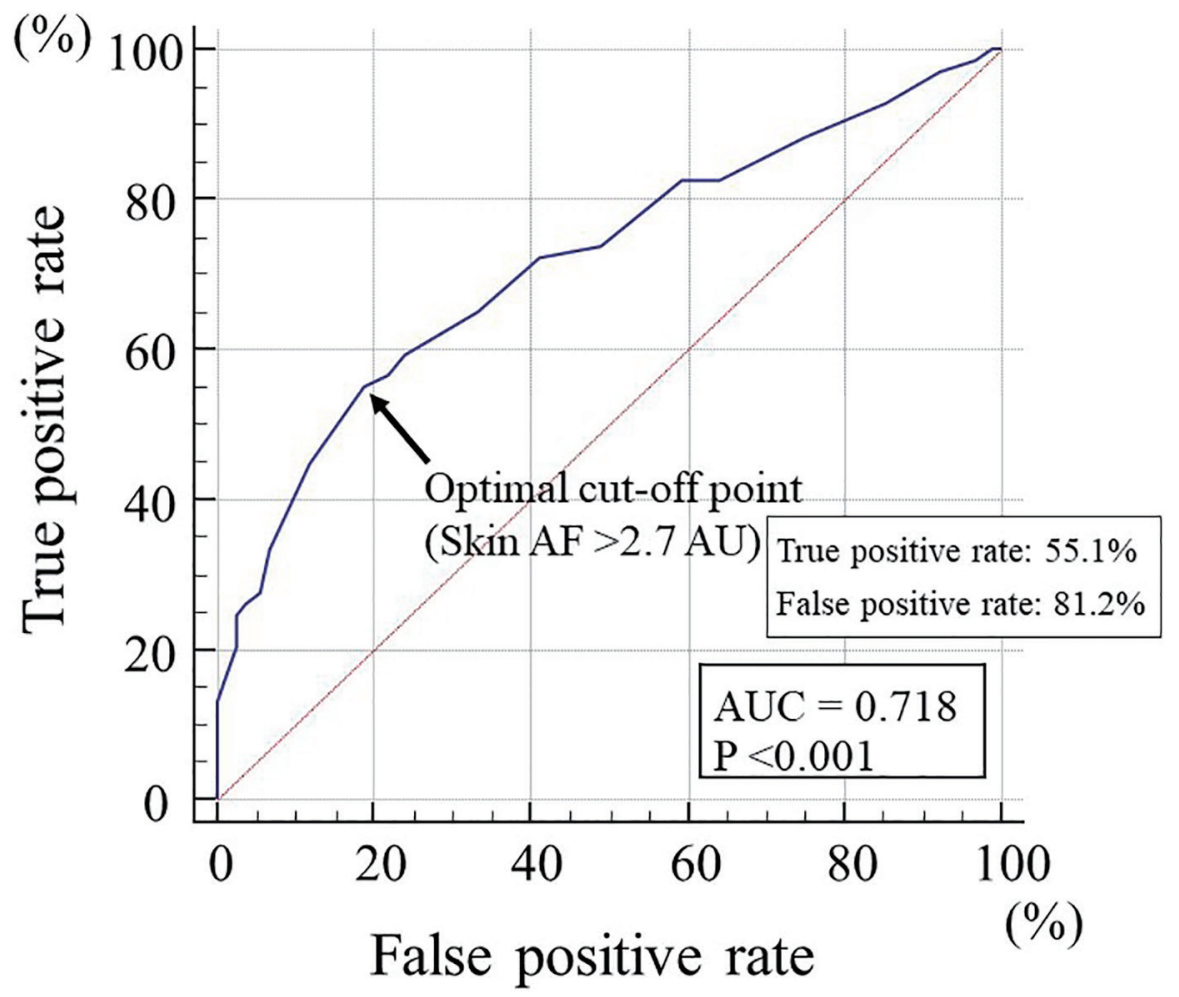

Figure 5. The receiver-operating characteristic curve analysis for the detection of high CAVI based on skin AF. The maximum Youden's index indicated that skin AF of > 2.7 AU was the optimal cut-off point to determine the high CAVI of $\geq 9.0$. AF: autofluorescence; CAVI: cardio-ankle vascular index; AU: arbitrary unit; AUC: area under the curve.

smoking habits and CAVI, which can also be interpreted that smoking habits were important target factors to promote arterial dysfunction in patients with Mets. On the contrary, several studies reported that the smoke can affect AGEs production $[37,38]$. The results in this study also indicated that smoking habits or degree of smoking exposure were significantly associated with increased skin AF levels in patients with Mets. Thus, the results in previous and this study indicated that smoking cessation was strongly recommended for arterial function or AGEs production in patients with Mets.

Researchers emphasized that low-grade inflammation in the arterial wall plays a crucial role in the pathogenesis of atherosclerosis progression [39]. Indeed, several clinical studies have reported significant associations between inflammatory markers and CAVI $[40,41]$. This study also indicated that hsCRP was selected as independent variables for CAVI as a subordinate factor, indicating that inflammation acts an important role to promote arterial dysfunction in patients with Mets. On the contrary, several studies emphasized that AGEs or their receptors were associated with inflammation in Mets [42, 43]. This study also indicated that skin AF was significantly associated with hs-CRP in patients with Mets. On the contrary, medications such as statin or angiotensin receptor blocker were reported to decrease inflammation in the arterial wall $[44,45]$. In addition, these medications also decreased AGE levels [46, 47]. In this study, all patients had no medications. Therefore, these medications, that is, statin or angiotensin receptor block- er, were aggressively administered on patients with Mets with high skin AF levels, which consequently possibly decrease CVD events by decreasing inflammation and AGE levels.

The target cut-off levels of skin AF should be determined in order to predict abnormal CAVI levels in clinical settings. This study clarifies the clinical usefulness of assessing skin AF to detect CAVI as high as $\geq 9.0$, which is shown to be discriminatory of vascular failure by CAVI [48]. Receiver-operating characteristic curve analysis indicated that skin AF of $>2.7 \mathrm{AU}$ is the optimal cut-off point to discriminate high CAVI. Several cut-off levels of skin AF for CVD risk were reported [14, 49, 50]. Although true positive rate was relatively low, this study indicated that CVD events may be decreased in patients with Mets to maintain skin AF of $\leq 2.7$ AU. Lifestyle modification is undoubtedly one of the most important therapies to manage patients with Mets. In addition, Isami et al also reported that lifestyle habits such as physical activity, nonsmoking, adequate sleep, low mental stress level, eating breakfast and abstaining from sugary foods were independently associated with lower skin AF levels [51]. Therefore, good lifestyle habits are important to maintain lower skin AF levels in patients with Mets.

\section{Limitations}

This study had several limitations. First, a substantial number of patients did not undergo modalities, such as angiography, com- 
puted tomography, magnetic resonance imaging and echocardiography; therefore, asymptomatic CVD may have remained undetected. Second, female patients were not included in this study. A previous study indicated that the proportion of patients with Mets diagnosed according to the Japanese criteria in the general Japanese female population is extremely small compared to the male population (incidence: $12.1 \%$ in males, $1.7 \%$ in females) [52]. Therefore, Mets in females is very difficult to analyze in a single-unit range. The relationship between skin AF and CAVI in the Japanese female Mets population will be discussed in largescale studies. Finally, this was single-center cross-sectional study, and the sample size was relatively small. An additional large number of studies, including evaluations of interventional therapies, are required to clarify the clinical significance of skin $\mathrm{AF}$ as a risk factor for CVD in patients with Mets.

\section{Conclusions}

In conclusion, this study indicates that skin AF was independently associated with CAVI, indicating that skin AF may be an important CVD risk factor in Japanese male patients with Mets. In addition, the risk value of skin AF was considered as higher than 2.7 AU. Further investigations in a large number of prospective studies, including intervention therapies, are required to validate the results in this study.

\section{Acknowledgments}

The author is grateful to the individuals who participated in this study.

\section{Financial Disclosure}

None to declare.

\section{Conflict of Interest}

None to declare.

\section{Informed Consent}

All patients provided informed consent.

\section{Author Contributions}

The author was involved in preparing the study design as well as acquisition, analysis and interpretation of data.

\section{References}

1. Ford ES, Giles WH, Dietz WH. Prevalence of the met- abolic syndrome among US adults: findings from the third National Health and Nutrition Examination Survey. JAMA. 2002;287(3):356-359.

2. Ansarimoghaddam A, Adineh HA, Zareban I, Iranpour S, HosseinZadeh A, Kh F. Prevalence of metabolic syndrome in Middle-East countries: Meta-analysis of crosssectional studies. Diabetes Metab Syndr. 2018;12(2):195201.

3. Tadaki S, Sakata Y, Miura Y, Miyata S, Asakura M, Shimada K, Yamamoto T, et al. Prognostic impacts of metabolic syndrome in patients with chronic heart failure- a multicenter prospective cohort study. Circ J. 2016;80(3):677688.

4. Galassi A, Reynolds K, He J. Metabolic syndrome and risk of cardiovascular disease: a meta-analysis. Am J Med. 2006;119(10):812-819.

5. Mottillo S, Filion KB, Genest J, Joseph L, Pilote L, Poirier P, Rinfret $\mathrm{S}$, et al. The metabolic syndrome and cardiovascular risk a systematic review and meta-analysis. J Am Coll Cardiol. 2010;56(14):1113-1132.

6. Shirai K, Hiruta N, Song M, Kurosu T, Suzuki J, Tomaru T, Miyashita Y, et al. Cardio-ankle vascular index (CAVI) as a novel indicator of arterial stiffness: theory, evidence and perspectives. J Atheroscler Thromb. 2011;18(11):924938.

7. Endo K, Saiki A, Ohira M, Miyashita Y, Shirai K. Cardioankle vascular index may reflect endothelial function in type 2 diabetes. Int J Clin Pract. 2011;65(11):1200-1201.

8. Liu J, Liu H, Zhao H, Shang G, Zhou Y, Li L, Wang H. Descriptive study of relationship between cardio-ankle vascular index and biomarkers in vascular-related diseases. Clin Exp Hypertens. 2017;39(5):468-472.

9. Matsushita K, Ding N, Kim ED, Budoff M, Chirinos JA, Fernhall B, Hamburg NM, et al. Cardio-ankle vascular index and cardiovascular disease: Systematic review and meta-analysis of prospective and cross-sectional studies. J Clin Hypertens (Greenwich). 2019;21(1):16-24.

10. Hitsumoto T. Clinical Significance of Cardio-Ankle Vascular index as a cardiovascular risk factor in elderly patients with type 2 diabetes mellitus. J Clin Med Res. 2018;10(4):330-336.

11. Hitsumoto T, Shirai K. Factors affecting high-sensitivity cardiac troponin T elevation in Japanese metabolic syndrome patients. Diabetes Metab Syndr Obes. 2015;8:157162.

12. Laucevicius A, Ryliskyte L, Balsyte J, Badariene J, Puronaite R, Navickas R, Solovjova S. Association of cardio-ankle vascular index with cardiovascular risk factors and cardiovascular events in metabolic syndrome patients. Medicina (Kaunas). 2015;51(3):152-158.

13. Furuya F, Shimura H, Takahashi K, Akiyama D, Motosugi A, Ikegishi Y, Haraguchi K, et al. Skin autofluorescence is a predictor of cardiovascular disease in chronic kidney disease patients. Ther Apher Dial. 2015;19(1):40-44.

14. Noordzij MJ, Mulder DJ, Oomen PH, Brouwer T, Jager J, Castro Cabezas M, Lefrandt JD, et al. Skin autofluorescence and risk of micro- and macrovascular complications in patients with Type 2 diabetes mellitus-a multicentre study. Diabet Med. 2012;29(12):1556-1561. 
15. Hitsumoto T. Clinical Significance of Skin Autofluorescence in Patients With Type 2 Diabetes Mellitus With Chronic Heart Failure. Cardiol Res. 2018;9(2):83-89.

16. van Waateringe RP, Slagter SN, van Beek AP, van der Klauw MM, van Vliet-Ostaptchouk JV, Graaff R, Paterson AD, et al. Skin autofluorescence, a non-invasive biomarker for advanced glycation end products, is associated with the metabolic syndrome and its individual components. Diabetol Metab Syndr. 2017;9:42.

17. Matsuzawa Y. Metabolic syndrome - definition and diagnostic criteria in Japan. J Atheroscler Thromb. 2005; 12(6):301.

18. Hitsumoto T, Takahashi M, Iizuka T, Shirai K. Relationship between metabolic syndrome and early stage coronary atherosclerosis. J Atheroscler Thromb. 2007;14(6):294-302.

19. Meerwaldt R, Links TP, Graaff R, Hoogenberg K, Lefrandt JD, Baynes JW, Gans RO, et al. Increased accumulation of skin advanced glycation end-products precedes and correlates with clinical manifestation of diabetic neuropathy. Diabetologia. 2005;48(8):1637-1644.

20. Nomoto K, Yagi M, Arita S, Hamada U, Yonei Y. A survey of fluorescence derived from advanced glycation end products in the skin of Japanese: differences with age and measurement location. Anti Aging Med. 2012;9(5):119124.

21. Meerwaldt R, Graaff R, Oomen PHN, Links TP, Jager JJ, Alderson NL, Thorpe SR, et al. Simple non-invasive assessment of advanced glycation endproduct accumulation. Diabetologia. 2004;47(7):1324-1330.

22. Shirai K, Utino J, Otsuka K, Takata M. A novel blood pressure-independent arterial wall stiffness parameter; cardio-ankle vascular index (CAVI). J Atheroscler Thromb. 2006;13(2):101-107.

23. Friedewald WT, Levy RI, Fredrickson DS. Estimation of the concentration of low-density lipoprotein cholesterol in plasma, without use of the preparative ultracentrifuge. Clin Chem. 1972;18(6):499-502.

24. Matthews DR, Hosker JP, Rudenski AS, Naylor BA, Treacher DF, Turner RC. Homeostasis model assessment: insulin resistance and beta-cell function from fasting plasma glucose and insulin concentrations in man. Diabetologia. 1985;28(7):412-419.

25. Schisterman EF, Perkins NJ, Liu A, Bondell H. Optimal cut-point and its corresponding Youden Index to discriminate individuals using pooled blood samples. Epidemiology. 2005;16(1):73-81.

26. Osawa S, Katakami N, Kuroda A, Takahara M, Sakamoto F, Kawamori D, Matsuoka T, et al. Skin autofluorescence is associated with early-stage atherosclerosis in patients with type 1 diabetes. J Atheroscler Thromb. 2017;24(3):312-326.

27. Hitsumoto T. Clinical usefulness of the cardio-ankle vascular index as a predictor of primary cardiovascular events in patients with chronic kidney disease. J Clin Med Res. 2018;10(12):883-890.

28. Wang CC, Wang YC, Wang GJ, Shen MY, Chang YL, Liou SY, Chen HC, et al. Skin autofluorescence is associated with endothelial dysfunction in uremic subjects on hemodialysis. PLoS One. 2016;11(1):e0147771.

29. Yan SF, Ramasamy R, Schmidt AM. The RAGE axis: a fundamental mechanism signaling danger to the vulnerable vasculature. Circ Res. 2010;106(5):842-853.

30. Grossin N, Auger F, Niquet-Leridon C, Durieux N, Montaigne D, Schmidt AM, Susen S, et al. Dietary CMLenriched protein induces functional arterial aging in a RAGE-dependent manner in mice. Mol Nutr Food Res. 2015;59(5):927-938.

31. Suga T, Iso T, Shimizu T, Tanaka T, Yamagishi S, Takeuchi $\mathrm{M}$, Imaizumi T, et al. Activation of receptor for advanced glycation end products induces osteogenic differentiation of vascular smooth muscle cells. J Atheroscler Thromb. 2011;18(8):670-683.

32. Webb DR, Khunti K, Silverman R, Gray LJ, Srinivasan B, Lacy PS, Williams B, et al. Impact of metabolic indices on central artery stiffness: independent association of insulin resistance and glucose with aortic pulse wave velocity. Diabetologia. 2010;53(6):1190-1198.

33. Fakhrzadeh H, Sharifi F, Alizadeh M, Arzaghi SM, Tajallizade-Khoob Y, Tootee A, Alatab S, et al. Relationship between insulin resistance and subclinical atherosclerosis in individuals with and without type 2 diabetes mellitus. J Diabetes Metab Disord. 2015;15:41.

34. Uribarri J, Cai W, Ramdas M, Goodman S, Pyzik R, Chen $\mathrm{X}$, Zhu L, et al. Restriction of advanced glycation end products improves insulin resistance in human type 2 diabetes: potential role of AGER1 and SIRT1. Diabetes Care. 2011;34(7):1610-1616.

35. Miele C, Riboulet A, Maitan MA, Oriente F, Romano C, Formisano P, Giudicelli J, et al. Human glycated albumin affects glucose metabolism in L6 skeletal muscle cells by impairing insulin-induced insulin receptor substrate (IRS) signaling through a protein kinase $\mathrm{C}$ alpha-mediated mechanism. J Biol Chem. 2003;278(48):47376-47387.

36. Higashiyama A, Okamura T, Ono Y, Watanabe M, Kokubo Y, Okayama A. Risk of smoking and metabolic syndrome for incidence of cardiovascular disease-comparison of relative contribution in urban Japanese population: the Suita study. Circ J. 2009;73(12):2258-2263.

37. Cerami C, Founds H, Nicholl I, Mitsuhashi T, Giordano D, Vanpatten S, Lee A, et al. Tobacco smoke is a source of toxic reactive glycation products. Proc Natl Acad Sci U S A. 1997;94(25):13915-13920.

38. Nicholl ID, Bucala R. Advanced glycation endproducts and cigarette smoking. Cell Mol Biol (Noisy-le-grand). 1998;44(7):1025-1033.

39. Geovanini GR, Libby P. Atherosclerosis and inflammation: overview and updates. Clin Sci (Lond). 2018;132(12):1243-1252.

40. Kotani K, Yamada T, Miyamoto M, Kario K, Ishibashi $\mathrm{S}$, Taniguchi N. The correlation between the cardio-ankle vascular index (CAVI) and serum amyloid A in asymptomatic Japanese subjects. Heart Vessels. 2012;27(5):499504.

41. Higashiyama A, Wakabayashi I, Kubota Y, Adachi Y, Hayashibe A, Nishimura K, Sugiyama D, et al. Does highsensitivity C-reactive protein or low-density lipoprotein cholesterol show a stronger relationship with the cardio- 
ankle vascular index in healthy community dwellers?: the KOBE study. J Atheroscler Thromb. 2012;19(11):10271034.

42. Uribarri J, Cai W, Woodward M, Tripp E, Goldberg L, Pyzik R, Yee K, et al. Elevated serum advanced glycation endproducts in obese indicate risk for the metabolic syndrome: a link between healthy and unhealthy obesity? J Clin Endocrinol Metab. 2015;100(5):1957-1966.

43. Momma H, Niu K, Kobayashi Y, Huang C, Chujo M, Otomo A, Tadaura H, et al. Higher serum soluble receptor for advanced glycation end product levels and lower prevalence of metabolic syndrome among Japanese adult men: a cross-sectional study. Diabetol Metab Syndr. 2014;6(1):33.

44. Pirro M, Simental-Mendia LE, Bianconi V, Watts GF, Banach M, Sahebkar A. Effect of statin therapy on arterial wall inflammation based on 18F-FDG PET/CT: a systematic review and meta-analysis of interventional studies. J Clin Med. 2019;8(1):118.

45. Fujiwara Y, Shiraya S, Miyake T, Yamakawa S, Aoki M, Makino H, Nishimura M, et al. Inhibition of experimental abdominal aortic aneurysm in a rat model by the angiotensin receptor blocker valsartan. Int J Mol Med. 2008;22(6):703-708.

46. Mukai H, Svedberg O, Lindholm B, Dai L, Heimburger O, Barany P, Anderstam B, et al. Skin autofluorescence, arterial stiffness and Framingham risk score as predictors of clinical outcome in chronic kidney disease patients: a cohort study. Nephrol Dial Transplant. 2019;34(3):442448.

47. Forbes JM, Thomas MC, Thorpe SR, Alderson NL, Cooper ME. The effects of valsartan on the accumulation of circulating and renal advanced glycation end products in experimental diabetes. Kidney Int. 2004;66(Suppl 92):S105-S107.

48. Tanaka A, Tomiyama H, Maruhashi T, Matsuzawa Y, Miyoshi T, Kabutoya T, Kario K, et al. Physiological diagnostic criteria for vascular failure. Hypertension. 2018;72(5):1060-1071.

49. Lutgers HL, Graaff R, Links TP, Ubink-Veltmaat LJ, Bilo HJ, Gans RO, Smit AJ. Skin autofluorescence as a noninvasive marker of vascular damage in patients with type 2 diabetes. Diabetes Care. 2006;29(12):2654-2659.

50. Wang CC, Wang YC, Wang GJ, Shen MY, Chang YL, Liou SY, Chen HC, et al. Skin autofluorescence is associated with inappropriate left ventricular mass and diastolic dysfunction in subjects at risk for cardiovascular disease. Cardiovasc Diabetol. 2017;16(1):15.

51. Isami F, West BJ, Nakajima S, Yamagishi SI. Association of advanced glycation end products, evaluated by skin autofluorescence, with lifestyle habits in a general Japanese population. J Int Med Res. 2018;46(3):1043-1051.

52. Arai H, Yamamoto A, Matsuzawa Y, Saito Y, Yamada N, Oikawa S, Mabuchi H, et al. Prevalence of metabolic syndrome in the general Japanese population in 2000. J Atheroscler Thromb. 2006;13(4):202-208. 